\title{
British-Pakistani women's perspectives of diabetes self-management: the role of identity
}

\author{
Rabiya Majeed-Ariss, Cath Jackson, Peter Knapp and Francine M Cheater
}

Aims and objectives. To explore the effects of type 2 diabetes on British-Pakistani women's identity and its relationship with self-management.

Background. Type 2 diabetes is more prevalent and has worse outcomes among some ethnic minority groups. This may be due to poorer self-management and an inadequate match of health services to patient needs. The influence that type 2 diabetes has on BritishPakistani women's identity and subsequent self-management has received limited attention. Design. An explorative qualitative study.

Methods. Face-to-face semi-structured English and Urdu language interviews were conducted with a purposively selected heterogeneous sample of 15 British-Pakistani women with type 2 diabetes. Transcripts were analysed thematically.

Results. Four themes emerged: Perceived change in self emphasised how BritishPakistani women underwent a conscious adaptation of identity following diagnosis; Familiarity with ill health reflected women's adjustment to their changed identity over time; Diagnosis improves social support enabled women to accept changes within themselves and Supporting family is a barrier to self-management demonstrated how family roles were an aspect of women's identities that was resilient to change. The over-arching theme Role re-alignment enables successful self-management encapsulated how self-management was a continuous process where achievements needed to be sustained. Inter-generational differences were also noted: first generation women talked about challenges associated with ageing and co-morbidities; second generation women talked about familial and work roles competing with self-management.

Conclusions. The complex nature of British-Pakistani women's self-identification requires consideration when planning and delivering healthcare.

Relevance to clinical practice. Culturally competent practice should recognise how generational status influences self-identity and diabetes self-management in ethnically diverse women. Health professionals should remain mindful of effective self-management occurring alongside, and being influenced by, other aspects of life.
What does this paper contribute to the wider global clinical community?

- The research explored the experiences of first and second-generation British-Pakistani women with diabetes so as to capture how they themselves identified with, understood and made sense of their roles in the context of managing their health.

- Generational status influenced how women identified themselves and the subsequent impact on self-management. These generational differences may have important implications for nursing practice and ought to be considered when developing culturally competent services.

- The influence of diabetes on women's identity interacted with their ever-changing wider health issues and personal lives; this in turn had effects on their selfmanagement efforts. The complex nature of black and minority ethnic (BME) women's selfidentification requires consideration when planning and delivering healthcare to this group.
Authors: Rabiya Majeed-Ariss, PhD, MSc, BSc, Research Associate, School of Psychological Sciences, University of Manchester, Manchester; Cath Jackson, PhD, MSc, BA, Senior Research Fellow, School of Healthcare, University of Leeds, Leeds and York Trials Unit, Alcuin Research Centre, University of York, York; Peter Knapp, PhD, BA, RGN, Senior Lecturer, Department of Health Sciences, University of York, UK; Francine M Cheater PhD, MA,
RN, Professor and Director of Research, School of Health Sciences, Faculty of Medicine \& Health Sciences, University of East Anglia, Norwich Research Park, UK

Correspondence: Rabiya Majeed-Ariss, Research Associate, University of Manchester, Jean McFarlane Building, Oxford Road, Manchester, M13 9PL, UK.

E-mail: rmajeeda@gmail.com 
Key words: ethnic minority, ethnicity, identity, immigrant, Pakistani, race, selfmanagement, type 2 diabetes, women

Accepted for publication: 25 March 2015

\section{Introduction}

Globally, type 2 diabetes (T2D) is the fifth most common cause of death as well as being associated with a range of complications (Roglic et al. 2005). This worldwide prevalence is increasing (Shaw et al. 2010), particularly among black and minority ethnic (BME) groups who are at higher risk of developing the condition (Riste et al. 2001) and for whom health outcomes tend to be worse, just as they are for low-income groups (Imkampe \& Gulliford 2011). In the UK, South Asians have a higher prevalence of T2D and a greater risk of related complications and mortality (NDA 2010).

As for many long-term conditions, self-management is central to controlling diabetes (Kennedy et al. 2005). Diabetes self-management requires the patient to make multiple decisions daily in a complex regimen of diet, physical activity, glucose monitoring and medicine adherence (Clement 1995). These actions are largely based on patients' own knowledge, beliefs, attitudes, resources and support systems (Sakraida \& Robinson 2009). Patients' views of diabetes and self-management need to be better understood by policy makers and healthcare professionals.

\section{Background}

While there are comprehensive reviews evaluating diabetes self-management interventions delivered to BME groups (Saxena et al. 2007, Hawthorne et al. 2010), at the time of our work to our knowledge there were no systematic reviews of BME patients' views on T2D self-management. In response, we undertook a systematic review thematically synthesising international qualitative research focused on BME communities' views of multiple T2D self-management behaviours (Majeed-Ariss et al. 2013). A key emergent theme from the review was 'Importance of identity'.

In short, an individual's self-identity, for example, being a parent, partner, immigrant or person with diabetes, appeared to impact on self-management; and conversely participants' ability to self-manage affected self-identity. The review also noted that none of the included studies had specifically focused on self-identity. Indeed, existing research on identity and health behaviours has been predominantly quantitative (Pierro et al. 2003, Brouwer \& Mosack 2012) and has not captured how patients them- selves identify with, understand and make sense of their roles in the context of managing their health. It is anticipated that such an understanding may help nurses and other health professionals to better support people to effectively self-manage their diabetes.

Building on that review, the qualitative interview study presented here aimed to explore the views of British-Pakistani women to answer the research question: 'How does having T2D affect British-Pakistani women's identity and how does this relate to their subsequent self-management?' For the purposes of this study, the concept of identity was understood according to Identity Theory (Burke \& Tully 1977). This categorises the principal component of identity, as occupying 'roles' (e.g. mother, friend, person with a health condition) with associated meanings and expectations which need to be incorporated into the self to be performed (Burke \& Tully 1977).

\section{Methods}

\section{Design}

This was an exploratory qualitative study. Approval for the study was secured from the University of Leeds, School of Healthcare Research Ethics Committee (SHREC/RP/165).

\section{Participants and recruitment}

Participants were British-Pakistani adult women diagnosed with T2D living in Teesside, England. Purposive sampling (Maxwell 1997) was employed to provide diversity in immigration and education status, as these characteristics were considered potentially relevant to how women selfidentified and managed their condition. Education status was qualified differently for first and second generation women; for first generation immigrants, it referred to their ability to read and speak English; for second generation women it was whether or not they had obtained educational qualifications of at least G.C.S.E level (qualifications usually obtained at age 16).

English and Urdu language posters and participant information sheets advertising the study were displayed in mosques and Asian food shops. In addition, the researcher (RM) verbally introduced the study in Urdu at a local com- 
munity health education class being delivered to Pakistani women. Interested women were later contacted, when questions about the study were answered and they could decide whether or not they wished to participate. 'Snowballing' (Cameron 2005) also occurred naturally with participants informing friends and family about the study.

\section{Data collection}

Data were collected using semi-structured interviews from October 2009 to January 2010. The interview schedule (see Table 1) was informed by the findings of the systematic review (Majeed-Ariss et al. 2013) and the concept of identity.

Informed consent was obtained to undertake audiorecorded interviews, all of which took place at home (by participants' choice). Urdu language interviews were trans-

Table 1 Interview schedule

\begin{tabular}{l} 
Firstly, I would like to ask about the early experiences you had \\
when you learnt that you had type 2 diabetes? \\
- How did you feel at that time? \\
I would like to ask you to think about how you feel now about \\
your diabetes? \\
- Do these feelings have any effect on managing your diabetes? \\
I now want to ask you some questions about diabetes and your \\
different roles in everyday life. We know that women have \\
different roles in their day-to-day lives. For some women these \\
may affect their diabetes self-management. While for other \\
women they may not \\
What is the case for you in terms of your family life where you \\
may be mothers, daughters and wives? Do these roles affect your \\
diabetes management? In what way? \\
- Has having diabetes affected your family life compared to \\
before? In what way? \\
What is the case for you in terms of your diabetes and your social \\
life? Do these social roles have an effect on your diabetes \\
management? In what way? \\
- Has having diabetes affected your social life compared to \\
before? In what way? \\
What is the case for you in terms of your diabetes and your work \\
life? Do these work roles have an effect on your diabetes self- \\
management? In what way? \\
- Has having diabetes affected your work life compared to \\
before? In what way? \\
It seems from what you say that your previous roles and \\
responsibilities did/did not change since the diabetes diagnosis? \\
Do you think this is the same for men as it is for women? \\
Do you think this is the same for younger/older women? \\
Have you seen any change in family/friends/colleagues roles and \\
responsibilities as the result of your illness? \\
Do you think this is the same for men as it is for women? \\
Do think this is the same for younger/older women? \\
\hline
\end{tabular}

lated and then fully transcribed in English; English language interviews were transcribed verbatim.

\section{Data analysis}

Thematic analysis was used to distil patterns of data and thereby identify and report themes (Braun \& Clarke 2006). The research team developed an initial coding frame informed by concepts including identity, confidence and roles. The coding frame was then applied flexibly to the remaining transcripts using QSR Nvivo to manage the data. Codes were constantly reviewed to ensure that they captured the meanings in the data. Similarities and differences within and across immigration and education status were considered. Key themes were identified and these are reported in the following section.

\section{Findings}

\section{Participants}

Fifteen women participated; four responded to posters, six were recruited via the health education class and five were recruited through 'snowballing'. After 15 interviews, no new information was arising; women were giving familiar explanations around the same themes and so we considered the data to have reached saturation (Morse 1989).

All the women had T2D and were British-Pakistani Muslims with children, living in Teesside, England. Participants' ages ranged from 31-76 years old. Immigrant status was related to participant age: first generation participants were 43-76 years (median 55), while second generation participants were 31-55 years (median 45). Further demographic details are in Table 2.

\section{Emerging themes}

Four themes and one over-arching theme emerged from the interview data. The four themes will now be presented in turn, illustrated with quotes. Links between themes will be indicated, and finally the over-arching theme will be considered.

\section{Familiarity with ill health}

Ten participants remarked on having first degree relatives with T2D. Participants' prior experience of T2D often influenced how they sought and/or reacted to their diagnosis.

Women's recollections of their diagnosis varied greatly. Three participants described experiencing prolonged poor health before eventually being diagnosed with the condi- 
Table 2 Description of participants

\begin{tabular}{|c|c|c|c|c|c|c|c|c|}
\hline $\begin{array}{l}\text { Participant } \\
\text { (pseudonym) }\end{array}$ & $\begin{array}{l}\text { Generation } \\
\text { status }\end{array}$ & $\begin{array}{l}\text { Year } \\
\text { diagnosed }\end{array}$ & $\begin{array}{l}\text { Age } \\
\text { (years) }\end{array}$ & $\begin{array}{l}\text { Speaks } \\
\text { English well }\end{array}$ & GCSEs + & Work & Marital status & Co-morbidities \\
\hline Saliha & $2 \mathrm{nd}$ & 2005 & 31 & - & Yes & No & Married & High blood pressure \\
\hline Sughra & $1 \mathrm{st}$ & 2006 & 55 & Yes & - & Retired & Married & Arthritis \\
\hline Shahnaz & $1 \mathrm{st}$ & 1993 & 61 & No & - & Retired & Widow & Arthritis, thyroid, hernia \\
\hline Zakia & $1 \mathrm{st}$ & 1992 & 48 & No & - & Yes & Married & None \\
\hline Sajida & $1 \mathrm{st}$ & 2004 & 55 & No & - & No & Divorced & Arthritis, thyroid. \\
\hline Khalida & $1 \mathrm{st}$ & 1989 & 54 & No & - & No & Married & $\begin{array}{l}\text { Arthritis, high } \\
\text { blood pressure }\end{array}$ \\
\hline Maleha & $2 \mathrm{nd}$ & 2002 & 47 & - & No & Voluntary & Married & None \\
\hline Asifa & $1 \mathrm{st}$ & 2007 & 62 & Yes & - & No & Married & M.E., Cancer \\
\hline Shazia & 2nd & 2005 & 38 & - & Yes & Yes & Married & None \\
\hline Zohra & $1 \mathrm{st}$ & 1999 & 76 & Yes & - & No & Widow & Arthritis, Cyrisis \\
\hline Amaani & $1 \mathrm{st}$ & 2001 & 53 & No & - & No & Divorced & Arthritis \\
\hline Asiya & 2nd & 2001 & 49 & - & No & Voluntary & Divorced & $\begin{array}{l}\text { Arthritis, cholesterol, } \\
\text { asthma, ulcers }\end{array}$ \\
\hline Madah & $1 \mathrm{st}$ & 1986 & 71 & Yes & - & Retired & Married & $\begin{array}{l}\text { High blood pressure, } \\
\text { cholesterol }\end{array}$ \\
\hline Shakrah & 2nd & 1996 & 55 & - & Yes & Yes & Married & $\begin{array}{l}\text { High blood pressure, } \\
\text { cholesterol }\end{array}$ \\
\hline Sara & $1 \mathrm{st}$ & 2010 & 43 & No & - & No & Married & $\begin{array}{l}\text { Heart problems, } \\
\text { iron deficiency }\end{array}$ \\
\hline
\end{tabular}

tion. These were the first generation women with the weakest English language skills in the sample. For another six participants their family history of T2D meant they were alert to the symptoms and this was a trigger to presenting themselves to a health professional and seeking diagnosis:

I had a sort of idea because my mother had it and um I sort of knew what diabetes are because I was already um looking after a person with diabetes. Asiya - 2nd generation

Familiarity with family members' diabetes also influenced how participants assessed their own self-management. Several women noted the shortcomings in their families' selfmanagement as compared to their own:

Since I have had diabetes I have been using sweetener, my mother doesn't like it she just uses normal sugar. Even though doctors have really tried to explain to her, we have said to her as well that "Mum this is not good for your health". But my Mum says that “when I have that in my tea I don't like the smell and I can't drink my tea”, so she won't take sweetener. But I made these changes as soon as I found out I had diabetes. Sara - 1st generation

Shazia was an interesting exception. She attributed her less strict management to her father-in-law's experience with the condition: his diabetes was controlled strictly yet he died five years after diagnosis:

My father-in-law was diabetic and he was type 2 as well, he was just on medication. And with him we all took it to heart that it was a big illness and everything and we totally cut down all fats and all his sugars. And we thought it wasn't really fair, we stopped him from a lot of stuff, you know, like a lot of food which "oh that's no good for you", you know, he totally cut down on everything. And with me I think I find it easier if you stick to everything but everything has a limit. Shazia -2 nd generation

Participants' recollections of their reactions to diagnosis were divided. Eight women described positive feelings while in contrast, the other seven described negative feelings. Women describing positive feelings spoke about their familiarity with ill health, either from family members' diabetes or their own experience of another health condition. They reported prior experiences as 'constructive' as they felt more prepared to put their energies into practical management:

Like my dad had it... we've been through all that, we used to cook separate for him, we used to make separate, and I knew like what it does to you and how you can control it because we had it in the house before. Maleha - 2nd generation

Interestingly, the women who described negative feelings soon after diagnosis also mentioned familiarity with ill health (their family's or their own) as influential. In their case, negative past experiences caused concern for the future:

I already had heart problems from before and I had real iron deficiency and obviously when they told me about this I thought, well 
I'd seen the state of my mother. My mother has such pain, such problems, her kidneys are suffering and I was thinking these things could happen to me as well later in life. Sara - 1st generation

When describing their current feelings about their condition, most participants were positive and generally described feeling in control:

In the start I used to, it was difficult to control. I used to wonder how am I going to control it, what am I going to do to control it, why should I control it? Thankfully now it's controlled so I don't think about it. Shahnaz - 1st generation

Four participants, however, described their current feelings as negative. Two women, Khalida and Amaani, had limited English and described feeling dependent on others and confused about their condition:

I need help with everything, if I go to town I need help, if I go to the doctor's or the hospital I need help. Sometimes I need help cooking the dinner, I can't get up all the time. I need help with everything but ... all the children need to get on with their own jobs. Amaani - 2nd generation

Most participants themselves reflected on how they had adapted to their diabetes and how their self-management improved as they became more familiar and better adjusted to living with their condition. An example is how some participants emphasised undergoing a learning process in recognising and overcoming the symptoms of low and high blood sugar:

I think after three or four years now I know when my blood sugar is high, how I feel if it is low... I'm much more prepared now. In a way I'm much more organised comparing to the first time when I was diagnosed with diabetes. Sughra, 1 st generation

This emphasis on change over time has links with the theme 'Perceived change in self'.

\section{Diagnosis improves social support}

This theme comprised two subthemes: 'Family provides social support' and 'Share diabetes information with friends.'

Family provides social support. All participants said that diagnosis had increased the support they sought and received from their children and husband; women's attitudes towards this were largely positive. Half of the participants stated that their family supported their self-management in an indirect and practical way, most commonly in the completion of household chores. Only two participants said they had familial support with direct manage- ment of their condition. Saliha said her husband knew what to do in case of a hypoglycaemic attack while Sajida said her daughters advised her on an appropriate diet. The two women with the most limited English, Khalida and Amaani, said that while their families helped translate medical advice, they felt largely unsupported by them:

At first they (family) didn't take notice that much. Only when I get really ill, they think she's ill, she needs help. They don't do it straightaway. They can't feel it, how bad that person's doing. They cannot feel it. It makes you sad that why aren't people in the house realising what I'm going through. Khalida -1 st generation

Extended families on the other hand, were perceived as less supportive by some participants of both generations. These women talked about how South Asian cultural expectations could make them feel isolated or misunderstood:

-Some days I want to meet people but often I don't go out because of the diabetes. I worry what the wider family would say... "she was ill so why did she go out?" I think that, so I don't bother going out too often. Khalida -1 st generation

-Last time somebody passed away I had to go to London and the food they gave us I wasn't happy with it. I thought, well that's no good for me... the flour they'd used was white and you know, the curry they gave us was like loaded with a pile of "ghee" on it and I'm looking at it and thinking "I can't eat this". And then I can't remember who was next to me and she goes, "shut up and just have it". Shazia - 2nd generation

Share diabetes information with friends. Friends were mentioned less often than family in the context of managing diabetes, and mostly in the context of practical support and as a source of shared experiences. The benefit of obtaining information from friends was evident even amongst participants who demonstrated a good understanding of diabetes and keen self-management practices. Social support was crucial in Amaani's case, who explained that her limited English meant she felt very dependent on others:

My eyes wouldn't open, I had no energy in my body. I didn't know my sugar was low... my friend who lives nearby came round and she said to me "drink coke and you'll be ok". I said "how is coke going to make me better?” I never really used to drink it. She said to me "just try it", and indeed as I drank it, it felt like energy was returning to my body. My eyes opened wide, before they were shutting because I didn't even have the energy. Amaani-2nd generation

There was also a lot of talk around the value of traditional remedies particularly amongst first generation 
women. Several women emphasised the importance of sharing this knowledge and testing recommendations:

I do everything to stop me getting worse, anything. I even tried having raw kerela [bitter gourd] and even tried having rotten medication somebody brought from India - it was disgusting... I'll try anything. Herbal remedies and all sorts. Shakrah -2 nd generation

Other people say after taking this and that, you know, like herbs and they get better, and I always find out which herbs they are taking, what they are doing. Then I do that myself. Because you know, from your heart you want to get better. Zohra - 1st generation

Women's views' on the effectiveness of these behaviours, however, was mixed:

Our people [Asians] they don't eat natural herbs and that, don't eat fruits. You know, we have people that just sit down with their illness, just with their prescribed medications, just sit with them. "Got to take my tablets because my sugar's gone high" this and that. You should also do natural things. Sajida -1 st generation

Some eat kerela [bitter gourd], drink kerela water. That's homeopathic, I don't know. No that won't do anything, just eat sensibly, you must have chapatti right, eat roti nicely and have a cup of tea, have your tablets and you will be okay. Asifa - 1st generation

This sub-theme has links with the theme 'Familiarity with ill health' where women emphasised the importance of using other people's experiences of diabetes.

\section{Supporting family is a barrier to self-management}

An important role for participants was supporting their families in their roles as wife, mother and daughter-in-law. Women perceived putting the family's needs before their own as a key barrier to self-management:

Looking after him would affect my health. Sometimes I would be unwell in myself and I would be tired and would not want to do any work. But my husband was so poorly that I had to. He stayed in hospital a lot, going, coming back, visiting, doing everything with young children. Shahnaz - 1st generation

Other women commented more broadly that their family roles and responsibilities meant their own ability to look after their own health with respect to managing their condition could suffer:

There is some times if I'm too busy, then I will just eat what I've cooked for everybody, because I don't have some time to make something for myself. Maleha -2 nd generation

All participants considered the most important familial responsibility to be the care of young children. Mothers with young children talked about feeling rushed and having conflicting priorities. Older women recalled that management of their diabetes had been harder when their children were younger. Women with grown-up children talked about feeling generally supported by their offspring, although two women offered an alternative view. Khalida and Amaani, the two participants with the most limited English, held views that suggested they sometimes felt unsupported by their families:

Things looked blurry, lop-sided. I was in bed, and the pictures hanging on the wall, I couldn't see them well. I told my daughter "I can't see well". Before they all used to think I was just saying it, just joking, but one day I was sitting and I said "Seriously I can't see, take me somewhere" and they took me to the optician. The optician said "Yes, it's leaking at the back", now they are trying laser treatment but it's not working. Khalida -1 st generation

First and second generation women frequently commented that men with diabetes sought and received more practical family support than they did, particularly from spouses. Madah's and Shakrah's husbands had T2D and they spoke from that experience:

My husband had diabetes after I got it. He got it later on you can say 10-12 years back... So I have to control his diet and his things, "You should take care of your feet. You should go for a walk. You should eat this. You should eat not this one." So my experience is that um men they don't care for you but you have to care for them. Madah - 2nd generation

Men think oh just because you've got diabetes you're really ill. My husband is diabetic and he thinks he's really ill, oh I can't do this I'm diabetic. But he will eat everything. He will eat anything and everything, sweets, "barfi" and all that, he'll eat anything and everything. He thinks everybody should pity him. Even though I'm higher diabetes than him I take more tablets than him [laughs]... I think he does want people to do things for him. Shakrah - 2nd generation

While several participants had noted that it was harder for women to effectively manage their diabetes, others talked about how self-management was more difficult for men because they had the added pressure of paid work. None of the women who said this, had experience of doing paid work and all but one of them was a first generation immigrant:

Men I think they are more stronger than women. They will go out some times and they have to go to do the job. With diabetes they can't stay in, they're working in a factory or an office anyway. And they are more stronger than ladies, you know... Physically and mentally. Asifa - 2nd generation 
There are links between this theme and the sub-theme 'Family provides practical support', illustrating the reciprocal supporting roles between people with diabetes and their families.

\section{Perceived change in self}

Women made comparisons with their 'old self' reflecting perceived identity changes as a result of the condition. They spoke about how diabetes had changed their work roles both inside and outside the home; most commonly, described by almost half of the women, in relation to their stamina for housework:

The house also used to be clean, clean it, do this, do that, do everything. Now not as much. I still do it! But not like before, when I eagerly did this, did that, did my gardening, did everything, now not as much. That's happened, that's changed a lot. Shahnaz, 1st generation

The eight women who had experience of paid work gave mixed views on the effects diabetes placed on their ability to work; half felt that diabetes did not influence their work while the other half said that it did, and described a range of examples. Shakrah said that her sight suffered when she got tired and when working as a seamstress she had to stop and take breaks. Sughra began to feel exhausted in the evenings and eventually took early retirement from teaching. For Shazia the main struggle was not being able to take regular breaks to eat, as she worked in a shop and could not stop if it was busy. In contrast, Asiya reported her work as having a positive effect on her diabetes, as she worked with people with mental health problems and said this gave her courage to 'fight' her own condition.

As well as changes in their work roles, women talked about changes to physical well-being since diagnosis; these were related to their age and co-morbidities. The notion of age was raised by three women who expressed some confusion as to whether their being unable to undertake tasks they could previously complete, was related to their diabetes or growing older. Similarly, co-morbidities made it difficult for some women to infer which condition was responsible for how they felt:

When I'm tired I have to rest, but I don't know if I'm tired now with the diabetes or with the M.E. [Myalgic Encephalopathy]. Asi$\mathrm{fa}-1$ st generation

This theme has links with the sub-theme 'Own experiences of illness,' where by women emphasised perceived changes over time in their bodies' response to the condition.

As well as making comparisons with themselves prediagnosis, participants compared themselves with others without diabetes, placing an emphasis on being 'normal' and wanting to retain normality in their day-to-day living. Shazia and Madah tried not to worry and continue as 'normal', whereas Khalida and Saliha had feelings of inadequacy compared to other ('normal') people who did not live with diabetes.

It is important to note that the two interviewees, Khalida and Saliha, were mother and daughter and both used insulin. Both of their views detailed not feeling 'free' to socialise because of the demands of their condition, such as remembering medicines before going out, eating on time and the possibility of becoming unwell. These descriptions suggested that they found it hard to be spontaneous in their lives. This similarity in mother and daughter views has links with the theme 'Familiarity with ill health' where participants drew comparisons between themselves and their families' self-management.

\section{Role re-alignment enables successful self-management}

The over-arching emergent theme captured how women themselves considered diabetes to have had an impact on how they perceived their identity and the subsequent adaptations that they and others were required to make, for effective self-management. In each individual theme, beliefs and attitudes around self-identity emerged that support this over-arching theme.

The theme 'Perceived change in self' suggested that women's role re-alignment was adopted consciously to overcome the resultant changes of a diabetes diagnosis, which had made them feel different from their 'old self' and 'normal'. 'Familiarity with ill health' also related to participants' adjustment to their roles over time, which enabled effective self-management. The theme 'Diagnosis improves social support' can be interpreted to mean social support that helped women accept changes in themselves that were a result of their diabetes and subsequently helped them with self-management. In the theme 'Supporting family is a barrier to selfmanagement', women again acknowledged diabetes to have affected their personal lives. In this instance, however, women often spoke of resistance to re-aligning familial roles to improve self-management; although they recognised that supporting their family often competed with the demands of self-management. This suggests successful achievement of familial roles was an important aspect of their identity, and as such was resilient to change. Participants valued the support they received from, and provided to others - an important reciprocal role within their self-identities.

It was clear that competing roles challenged their ability to effectively manage their diabetes. Diabetes self-management was undertaken in addition to their already multiple roles as mother, wife, friend, neighbour, employee, colleague, etc. Central to how diabetes affects an individual's identity is 
how the individual balances and revises existing roles alongside the integration of new ones.

\section{Discussion}

This study aimed to better understand how living with T2D affects British-Pakistani women's identity and how this relates to diabetes self-management. Two key issues became apparent in this study: the first was the influence of generational status on self-identity and its subsequent impact on their ability to self-manage; the second was change over time, in the roles patients identified with and how they self-managed their T2D.

The influence of generational status was evident. Predominantly first generation British-Pakistani women spoke of sharing information on alternative remedies with their friends. This is supported by Pieroni et al. (2008) who found traditional medicines to be popular amongst the British-Pakistani population but that knowledge had decreased among younger generations. Communicating with peers, with whom they shared health beliefs, may have allowed first generation women to retain aspects of their cultural identity in their approach to diabetes self-management in a way that was less important to second generation women. This is consistent with the theories of assimilation and acculturation (Landrine \& Klonoff 2004).

The data emphasised the reciprocal roles of support in British-Pakistani women's lives. While the majority of participants perceived British-Pakistani men with diabetes to receive more direct familial support, there were some interesting inter-generational differences. Principally, first generation women spoke in Urdu about how self-management was more difficult for men because they had the added pressure of paid work. Conversely, second generation participants spoke in English and emphasised that self-management was more difficult for women because they often undertook it alongside both traditional family caring responsibilities and paid work. Again, the theories of acculturation and assimilation (Landrine \& Klonoff 2004) suggest an explanation for why generational status has such effects on identities and how this impacts on self-management of their condition.

This issue of generational status relates to an important distinction in Identity Theory; that of group and role based identities (Stets \& Burke 2000). A group identity is being at ease in a social context with a particular group, having similarities with them (e.g. having traditional family caring responsibilities) or sharing an outlook with them (e.g. on the merit of alternative remedies in diabetes management). A role identity on the other hand involves behaving in a manner that fulfils role expectations, by negotiating with others or manipulating an environment to control resources or influence. In this study, role identities were evidently different for first and second generation participants, whereas group identities held more similarities.

The second key emergent issue was change over time; particularly how women identified themselves and how they managed their condition. Participants were noted as recalling either positive or negative feelings at diagnosis. Women with positive recollections had sought out diagnosis by presenting to healthcare services with symptoms they suspected as being related to diabetes, often prompted by a family history. Similarly, Peel et al. (2004) found that White Scottish participants who had anticipated the diagnosis due to a familiarity with the condition were better able to adjust to their altered identity. The majority of the British-Pakistani women in this sample were positive about the present, feeling largely in control of their diabetes in contrast to their reflections on past feelings. This suggests that experience was instrumental in facilitating acceptance of an altered identity.

The notion of time re-emerged in the over-arching theme 'Role re-alignment enables successful management', making the point that while diabetes affects a person's roles, it is the process of suitably re-aligning those roles that is crucial for successful self-management. This emphasised how patients' adjustments to their changed roles is an ongoing process that facilitates self-management. Changes in women's health (e.g. ageing, new symptoms, co-morbidities) alongside their personal lives (e.g. children becoming ill, losing their job, bereavements) made it challenging to sustain effective selfmanagement. This finding is consistent with other published work on long-term conditions that considers adaptation to self-management as a 'lifetime task' (Lorig \& Holman 2003). Furthermore, this finding that an individual holds various roles is congruent with the Identity Theory, where the self is multifaceted as result of its ability to be reflexive and identify itself in relation to its context (McCall \& Simmons 1978). For example, an individual may identify at any point with being a mother, a wife, an immigrant and a person with diabetes; and self-identity can vary according to circumstance (i.e. over time) and belief system (i.e. inter-generationally).

Acculturation and assimilation theories (Landrine \& Klonoff 2004) can explain why generational status affects British-Pakistani women's identities and how this impacts upon subsequent self-management. This may have important implications for practice because what is culturally appropriate care for first generation patients may not be suitable for second generation patients who, as is suggested by these findings, are likely to face a different set of challenges. Women's need to continually self-manage diabetes alongside other aspects of their life due to the condition's lifelong nature and 
the multi-faceted self (Stets \& Burke 2000), emphasises that self-management is ongoing. This evidence suggests that health professionals should stay mindful of patients' potential need for continuing support. This is particularly true if patients experience a significant change in another realm of their life, such as a bereavement, as this could have a consequential effect on diabetes self-management.

\section{Strengths and limitations}

A key strength is the study's purposive sampling, which enabled exploration of data patterns according to different characteristics. However, migrant generation status was confounded with both age and years since diagnosis, which made it hard to disentangle these different potential influences. Despite using purposive sampling, our sample was uniform in terms of being married and with children. This, however, is common to the population under study and in that regard could be considered to be fairly typical of the population of interest to this study. One of the strength of the study was reaching data saturation which provided confidence in the credibility of findings.

A limitation was that the study design lacked a comparison group of white British women. This would have made it possible to better determine the interplay and relative influence of cultural and gender identities, and their influences on diabetes self-management. Such information would prove useful for healthcare providers targeting treatments and self-management interventions. Also, over a third of participants were recruited from the same diabetes education class. These women may have been more likely to self-manage than the general population because they were sufficiently motivated to attend a T2D education class. An advantage of recruiting from this class, however, was that the researcher could introduce herself and the project verbally in Urdu. This may have helped recruit women from this more 'hard-to-reach' group.

\section{Conclusions}

The effect of immigrant generational status on how diabetes influences identity is an important consideration for sup- porting effective self-management in this population. The notion of time is also important. Patients' roles were continually modified (due to changes in their wider health or personal lives) as a result of which they needed to adapt how they identified themselves, to sustain effective selfmanagement.

\section{Relevance to clinical practice}

It should be noted that all study participants viewed their diabetes self-management as a continuous process that needed to be sustained alongside other aspects of their daily lives. The complex nature of BME patients' self-identification means this is an especially important consideration and one that may negatively influence selfmanagement in this group. Such women may require continuing and intensive support to enable them to effectively live with and self- manage their diabetes. Additionally, the inter-generational differences influences on identity and subsequent self-management needs to be considered when developing and delivering culturally competent services and self-management plans for a BME population.

Note: Names of the participants have been changed. Rabiya Majeed-Ariss undertook this study as part of a $\mathrm{PhD}$ degree funded by the School of Healthcare at the University of Leeds, UK.

\section{Acknowledgements}

The project was fully sponsored by a studentship from the University of Leeds, School of Healthcare.

\section{Disclosure}

The authors have confirmed that all authors meet the ICMJE criteria for authorship credit (www.icmje.org/ethical_ 1author.html), as follows: (1) substantial contributions to conception and design of, or acquisition of data or analysis and interpretation of data, (2) drafting the article or revising it critically for important intellectual content and (3) final approval of the version to be published.

\section{References}

Braun V \& Clarke V (2006) Using thematic analysis in psychology. Qualitative Research in Psychology 3, 77-101.
Brouwer AM \& Mosack KE (2012) "I am a blood sugar checker": intervening effects of self-as-doer identity on the relationship between self-efficacy and diabetes self-care behaviors. Self and Identity 11, 472-491. 
Burke PJ \& Tully J (1977) The measurement of role/identity. Social Forces 55, 881-897.

Cameron J (2005) Focusing on the focus group. In Qualitative Research Methods in Human Geography, 2nd edn. (Hay I ed). Oxford University Press, Melbourne, Vic., pp. 156-182.

Clement S (1995) Diabetes self-management education. Diabetes Care 18, 1204-1214.

Hawthorne K, Robles Y, Cannings-John R \& Edwards AG. (2010) Culturally appropriate health education for Type 2 diabetes in ethnic minority groups: a systematic and narrative review of randomized controlled trials. Diabetic Medicine 27, 613-623.

Imkampe AK \& Gulliford MC (2011) Increasing socioeconomic inequality in type 2 diabetes prevalence - Repeated cross-sectional surveys in England 1994-2006. European Journal of Public Health 21, 484-490.

Kennedy A, Gask L \& Rogers A (2005) Training professionals to engage with and promote self-management. Health Education Research 20, 567-578.

Landrine H \& Klonoff EA (2004) Culture change and ethnic-minority health behavior: an operant theory of acculturation. Journal of Behavioral Medicine 27, 527-555.

Lorig KR \& Holman HR (2003) Self-management education: history, definition, outcomes, and mechanisms. Annals of Behavioral Medicine 26, 1-7.

Majeed-Ariss R, Jackson C, Knapp P \& Cheater FM (in press) A systematic review of research into black and ethnic minority patients' views on selfmanagement of type 2 diabetes. Health Expectations. doi:10.1111/ hex.12080.

Maxwell J (1997) Designing a qualitative study. In Handbook of Applied Social Research Methods. (Bickman L \& Rog DJ eds). Sage, Thousand Oaks, CA, pp. 69-100.

McCall GJ \& Simmons JL (1978) Identities and Interactions. Free Press, New York.

Morse JM (1989) Qualitative Nursing Research: A Contemporary Dialogue. Sage, Newbury Park.

National Diabetes Audit (2010) National Diabetes Audit Executive Summary 2008/2009 [Online]. Available at: http://www.hqip.org.uk/assets/NCAPO P-Library/National-Diabetes-Audit-Exe cutive-Summary-2009-2010.pdf [Acce ssed 19 July 2010].

Peel E, Parry O, Douglas M \& Lawton J (2004) Diagnosis of type 2 diabetes: a qualitative analysis of patients' emotional reactions and views about information provision. Patient Education and Counseling. 53, 269275.

Pieroni A, Sheikh Q-Z, Ali W \& Torry B (2008) Traditional medicines used by Pakistani migrants from Mirpur living in Bradford, Northern England. Complementary Therapies in Medicine. 16, 81-86.

Pierro A, Mannetti L \& Livi S (2003) Selfidentity and the theory of planned behavior in the prediction of health behavior and leisure activity. Self and Identity 2, 47-60.

Riste L, Khan F \& Cruickshank K (2001) High prevalence of Type 2 Diabetes in all ethnic groups, including Europeans in a British inner city: relative poverty, history, inactivity or 21st century Europe. Diabetes Care 24, 1377-1383.

Roglic G, Unwin N, Bennett PH, Mathers C, Tuomilehto J, Nag S, Connolly V \& King H (2005) The burden of mortality attributable to diabetes: realistic estimates for the year 2000. Diabetes Care 28, 2130-2135.

Sakraida TJ \& Robinson MV (2009) Health literacy self-management by patients with type 2 diabetes and stage 3 chronic kidney disease. Western Journal of Nursing Research 31, 627647.

Saxena S, Misra T, Car J, Netuveli G, Smith R \& Majeed A (2007) Systematic review of primary health care interventions to improve diabetes outcomes in minority ethnic groups. Journal of Ambulatory Care Management 30, 218-230.

Shaw JE, Sicree RA \& Zimmet PZ (2010) Global estimates of the prevalence of diabetes for 2010 and 2030. Diabetes Research and Clinical Practice 87, 4 14.

Stets JE \& Burke PJ (2000) Identity theory and social identity theory. Social Psychology Quarterly 63, 224-237. 